Canadian Journal of Civil Engineering

Canadian

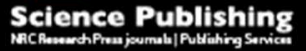

Revue canadienne de génie civil

\title{
Establishing the Fundamental Period of Light-Frame Wood Buildings on the Basis of Ambient Vibration Tests
}

\begin{tabular}{|r|l|}
\hline Journal: & Canadian Journal of Civil Engineering \\
\hline Manuscript ID & cjce-2017-0348.R1 \\
\hline Manuscript Type: & Article \\
\hline Date Submitted by the Author: & $19-$ Mar-2018 \\
\hline $\begin{array}{r}\text { Complete List of Authors: } \\
\text { Is the invited manuscript for } \\
\text { consideration in a Special } \\
\text { Issue? : } \\
\text { Doudak, Ghasan; University of Ottawa, } \\
\text { McClure, Ghyslaine; Civil Engineering and Applied Mechanics }\end{array}$ & Not Applicable (Regular Submission) \\
\hline Keyword: & $\begin{array}{l}\text { Timber structures; lateral drift; fundamental building period; stiffness; light } \\
\text { frame wood buildings; seismic analysis }\end{array}$ \\
\hline & \multicolumn{2}{|c}{} \\
\hline
\end{tabular}

SCHOLARONE ${ }^{\text {m }}$

Manuscripts 


\title{
Establishing the Fundamental Period of Light-Frame Wood Buildings on the Basis of Ambient Vibration Tests
}

\author{
Ghazanfarah Hafeez ${ }^{1}$, Ghasan Doudak ${ }^{2}$, Ghyslaine McClure $^{3}$
}

\section{ABSTRACT}

5 This research project deals with dynamic field testing of light-frame wood buildings with wood-

6 based shear walls. The primary objective of the investigation is to evaluate the building code

7 formula for estimating light- frame wood building's fundamental period for seismic analysis,

8 through intensive field testing and numerical modelling. The project also aims to propose an

9 alternative simplified rational approach to seismic analysis of these structures. The paper

10 presents ambient vibration (AV) testing results of light-frame wood buildings in Canada. The

11 dynamic characteristics of the measured buildings, such as natural frequency, mode shapes and

12 equivalent structural damping were obtained from Frequency Domain (FD) analysis of ambient

13 motion records. Using a simplified method of period estimation based on the Rayleigh

14 approximation while using the building mass and replacing the stiffness of shear walls by their

15 length showed reasonable fit when compared with the FE model results and AVT measured

16 periods. A formula was developed based regression analysis of tested buildings. The expression

17 is a function of building height, floor area and shear wall length and it was shown to provide a

18 reasonably good fit with the measured results.

\footnotetext{
${ }^{1} \mathrm{PhD}$ Candidate, Department of Civil Engineering, University of Ottawa, 161 Louis-Pasteur, Ottawa, ON K1N 6N5

${ }^{2}$ Associate Professor, Department of Civil Engineering, University of Ottawa, 161 Louis-Pasteur, Ottawa, ON K1N 6N5

${ }^{3}$ Professor, Department of Civil Engineering and Applied Mechanics, McGill University, 817 Sherbrooke Street West, Montréal, Québec, Canada, H3A 0C3
} 
20 Keywords: Timber structures; lateral drift; fundamental building period; stiffness; light frame

21 wood buildings; seismic analysis

\section{INTRODUCTION}

23 The dynamic characteristics of a structure determine its behavior under loading such as wind or

24 seismic action. Despite the transient nature of earthquakes and their dynamic effects on

25 buildings, many building codes around the world, including the National Building Code of

26 Canada (NBCC 2015), allow designers to analyze regular buildings (that are without significant

27 stiffness or mass irregularities) using equivalent static load methods due to their simplicity in

28 application. Also, the current Canadian building code provides procedures to determine wind

29 loads on structures of different types, but no specific guidance is provided to estimate the

30 fundamental frequency of a structure that should be considered when designing for wind load

31 effects.

32 For structures having light-frame wood shear walls as their lateral force resisting system, the

33 NBCC empirical formula for approximating the fundamental building period, $T_{a}$, for seismic

34 load calculation, is a function of only the building height, $h_{n}$ :

$T_{a}=0.05 h_{n}^{3 / 4}$

35 The NBCC also provides formulas to estimate the fundamental period of other structural systems

36 such as steel moment-resisting frames, reinforced concrete moment-resisting frames, other

37 moment-resisting frames, and steel braced frames, in relation to seismic design.

38 There are several issues associated with using the current NBCC (2015) period formula for light- 
39 frame wood structures, including its suitability for light frame wood shearwalls and the scatter

40 associated with the measured data even when compared with buildings on which the formula is

41 based. The coefficients and exponents in these formulas (e.g. Equation (1)) were derived based

42 on regression analysis using the fundamental periods measured for several buildings in

43 California during the 1971 San Fernando earthquake (ATC 1978). The measured data used for

44 the derivation of Equation (1) were taken on reinforced concrete shear wall buildings and large

45 scatter was observed in the collected data when the measured period was related to only the

46 height of the structures (Saatcioglu and Humar 2003). It is therefore questionable whether this

47 equation can reflect the fundamental periods of buildings of other materials (such as in light-

48 frame sheathed wood structures) and at different locations outside California where construction

49 practices may also significantly differ.

50 The current study provides a comprehensive database of light frame wood buildings and

51 develops an estimate for the building period that is more representative of this construction type.

52 An expression for an alternative building period is proposed in this paper which provides

53 significantly less spread in the data and incorporates key parameters that represent the building

54 mass and stiffness, rather than simply relying on the height of buildings, which is the case in the

55 current period formula (e.g. NBCC 2015).

56 The following sections provide a review of the available literature and highlight the needs for the

57 current study. The experimental and numerical investigations are described and comparison

58 between them established. Also, the alternative period formula is proposed and discussed.

\section{Previous attempts to improve the code period formula}


60 According to the NBCC, Equation (1) has general applicability to shear walls of various

61 materials, such as concrete, steel, and wood. Over the past few decades, the adequacy of this

62 equation has been questioned by researchers and efforts were made to suggest improvements.

63 Lagomarsino (1993) proposed a period formula as a function of building height based on

64 measurements made on 52 reinforced concrete buildings (including both concrete frame

65 buildings without shear walls and reinforced concrete shear wall buildings) in Italy. Farsi and

66 Bard (2004) performed ambient vibration tests on 35 reinforced concrete shear wall buildings

67 located in Grenoble, France, to identify the fundamental period of these buildings. The study also

68 provided an improved period equation as a function of building height. Gilles and McClure

69 (2012) established a database of modal properties of 39 concrete buildings located in Montreal

70 using ambient vibration testing. The study compared the measured fundamental periods with

71 those calculated from the NBCC formula (Equation (1)) and suggested an improved expression

72 which was linear with the height with coefficient of 0.020 .

73 Other studies proposed equations for fundamental period estimate that incorporated building plan

74 dimensions as variables in addition to building height. A study by Goel and Chopra (1998)

75 evaluated the code period equation specified in US building codes (NEHRP-94; SEAOC-96; and

76 UBC-1997) based on field measurements of nine concrete shear wall buildings during strong

77 ground motions in California. There was large scatter in the measured data when compared to

78 periods obtained by code equations. An improved formula was then suggested, which

79 incorporated a parameter related to shear wall dimensions. Lee et al. (2000) focused on the

80 evaluation of the period formula in the Korean building code using a data base of 50 reinforced

81 concrete shear wall buildings whose periods were measured using ambient vibration testing. The

82 authors proposed an alternative equation that incorporated the height of the building as well as 
83 the wall width per unit plan area. Saatcioglu and Morales (2011) also evaluated the code period

84 formula for concrete shear walls and frame buildings and proposed an equation that included the 85 moment of inertia (second moment of area of the building plan) and building height. The 86 proposed equation was derived from the data base of building periods obtained from 87 measurements during strong earthquake motions. The equation was linear with height but non88 linear with the moment of inertia, and it showed good correlation with the measured periods. A 89 recent study by Nikoo et al. (2017) developed the Self-Organization Feature Map (SOFM) 90 algorithm to estimate the fundamental periods of reinforced concrete shearwall buildings. The 91 building period estimates were compared to the periods obtained using FEMA-450, ATC3-06, 92 and the Costa Rican code equations. A database of measured periods of 78 reinforced concrete 93 shearwall buildings was assembled based on published data and used as a reference for the 94 comparison between the developed algorithm and the code. The study concluded that the SOFM 95 model was better capable of predicting the fundamental period values when compared with 96 estimates obtained from the code.

97 Fewer studies have been conducted on the dynamic characteristics of light-frame wood 98 buildings. Kharrazi $(2001 ; 2006)$ investigated vibration characteristics of low-rise timber 99 buildings using ambient vibration, forced vibration, and full-scale shake-table testing. His 100 research focused on single- and two-storey houses with different sheathing configurations using 101 laboratory shake table testing for validation. The study established a correlation between 102 measured periods during ambient and forced vibration tests, and resulted in empirical formulas to 103 increase the period measured by AVT to predict the period expected during strong shaking. 104 Kharrazi suggested two relationships for the fundamental frequencies of wood frame houses, 105 exposed to low (Equation (2)) and high (Equation (3)) levels of seismic excitation. 
$F_{V}=\propto 0.65\left(F_{A V}\right)^{1.1}$

$F_{V}=0.32\left(F_{A V}\right)^{1.4}$

107 Where $F_{V}$ and $F_{A V}$ are fundamental frequencies extracted from forced vibration and ambient 108 vibration test records, respectively. The factor $\propto$ in Equation (2) takes on the values of 0.76 , 1091.03 , and 1.42 for non-engineered, engineered and stucco houses, respectively.

110 The vibration behavior of wood-based buildings was also studied by Camelo (2003) who

111 developed a database of dynamic properties through analyses of available earthquake records on 112 five shearwall wood frame buildings instrumented by the California Strong Motion 113 Instrumentation Program, and by performing forced vibration testing on five other buildings 114 located in California. Eight sets of earthquake records were utilized to obtain the fundamental

115 frequency and damping ratio of one-, two- and three-storey wood frame buildings. Two full-scale 116 shake-table tests were also performed at University of California San Diego and University of 117 California Berkeley to validate the proposed period formula. The compiled database, excluding 118 the results of ambient vibration field testing, was analyzed to obtain the best fit curve for the 119 median fundamental period, $T$ as a function of building height, $h_{n}$ (in feet). The median period 120 formula, in Equation (4), was proposed to represent the seismic behavior of wood buildings 121 more accurately than the formula provided in the Uniform Building Code (UBC-97).

$T=0.032 h_{n}^{0.55}$ 
122 Hafeez et al. (2014) investigated the period formula in the National Building Code of Canada

123 through modeling of a light wood frame building using a finite element model. The study

124 estimated the building stiffness using the deflection equation for wood shear walls from the

125 current Canadian timber design standard (CSA 2014). The calculated fundamental periods using

126 a multiple-degree-of-freedom shear-building model were compared with the AVT results of a

127 light frame wood building. The study showed that the calculated periods based on the deflection

128 equation with no cumulative effect and those based on the shear wall tests stiffness were

129 consistent with the measured period values. The calculated period based on the deflection

130 formula including the cumulative effect yielded a value that was larger than the upper limit

131 stipulated by the NBCC (2015).

132 The above review of the state of knowledge clearly emphasizes the need for more investigation

133 of the dynamic characteristics of light-frame wood buildings for seismic analysis and

134 earthquake-resistant design. It is the aim of the current study to evaluate the adequacy of

135 contemporary code formulas for estimating the fundamental period of timber buildings,

136 specifically those consisting of light-frame wood shear walls, and develop a reliable expression

137 for building fundamental period based on field testing and numerical modelling. The essential

138 elements that define the research methodology are ambient vibration field testing, analysis of

139 recorded $\mathrm{AV}$ measurements, and stiffness estimation of lateral load resisting systems.

140 Ideally, building period measurements would be taken during a moderate to strong earthquake to

141 be more representative than ambient motion results for seismic design. Although these

142 measurements would still be uniquely associated with the particular seismic load characteristics,

143 the amplitude of building motions would be more representative of that experienced in actual

144 design-level earthquakes. However, measurements of dynamic motion of light-frame wood 
145 buildings during real earthquakes are rarely available, and field ambient vibration tests on a large

146 number of representative light-frame wood buildings are conducted, as an alternative, to create a

147 database. Numerical models of the tested buildings with their initial stiffness are developed, and

148 once validated using the AVT measurements the models are re-analyzed with higher force values

149 (reduced stiffness) and the fundamental periods are compared with expressions proposed in the

150 literature. Finally, regression analysis of the periods measured by AVT is also conducted to

151 develop a more reliable period formula to replace Equation (1) used in the NBCC for buildings

152 with light frame wood shearwalls as lateral load resisting systems.

153 MEASURED BUILDINGS

154 In total, 47 light-frame wood buildings of both regular and irregular layouts, located in moderate

155 to high seismic zones in Canada, were tested and analyzed. The locations, heights and plan 156 geometries of all tested buildings are provided in Table 1.

157 Table 1 Buildings tested using AVT method

\begin{tabular}{|c|c|c|c|c|c|c|}
\hline $\begin{array}{c}\text { Building } \\
\text { ID }\end{array}$ & Location & $\begin{array}{c}\text { No. of } \\
\text { Storeys }\end{array}$ & $\begin{array}{c}\text { Height } \\
\text { (m) }\end{array}$ & $\begin{array}{c}\text { Length } \\
\text { (m) }\end{array}$ & $\begin{array}{c}\text { Width } \\
\text { (m) }\end{array}$ & Geometry \\
\hline B1 & $\begin{array}{c}\text { Kamloops, } \\
\text { BC }\end{array}$ & $\begin{array}{c}5 \mathrm{~W}+1 \mathrm{C} \\
+\mathrm{B}^{*}\end{array}$ & 17.4 & 70 & 40 & \\
\hline B2 & $\begin{array}{c}\text { Kamloops, } \\
\text { BC }\end{array}$ & $\begin{array}{c}5 \mathrm{~W}+1 \mathrm{C} \\
+\mathrm{B}\end{array}$ & 17.4 & 89 & 70 & \\
\hline B3 & $\begin{array}{c}\text { Kamloops, } \\
\text { BC }\end{array}$ & $\begin{array}{c}5 \mathrm{~W}+1 \mathrm{C} \\
+\mathrm{B}\end{array}$ & 18.2 & 184 & 20 & \\
\hline B4 & $\begin{array}{c}\text { Quebec city, } \\
\text { QC }\end{array}$ & $6 \mathrm{~W}$ & 18 & 51.8 & 19.9 & \\
\hline B5 & $\begin{array}{c}\text { Kamloops, } \\
\text { BC }\end{array}$ & $4 W+1 C$ & 18.1 & 60 & 24 & \\
\hline
\end{tabular}




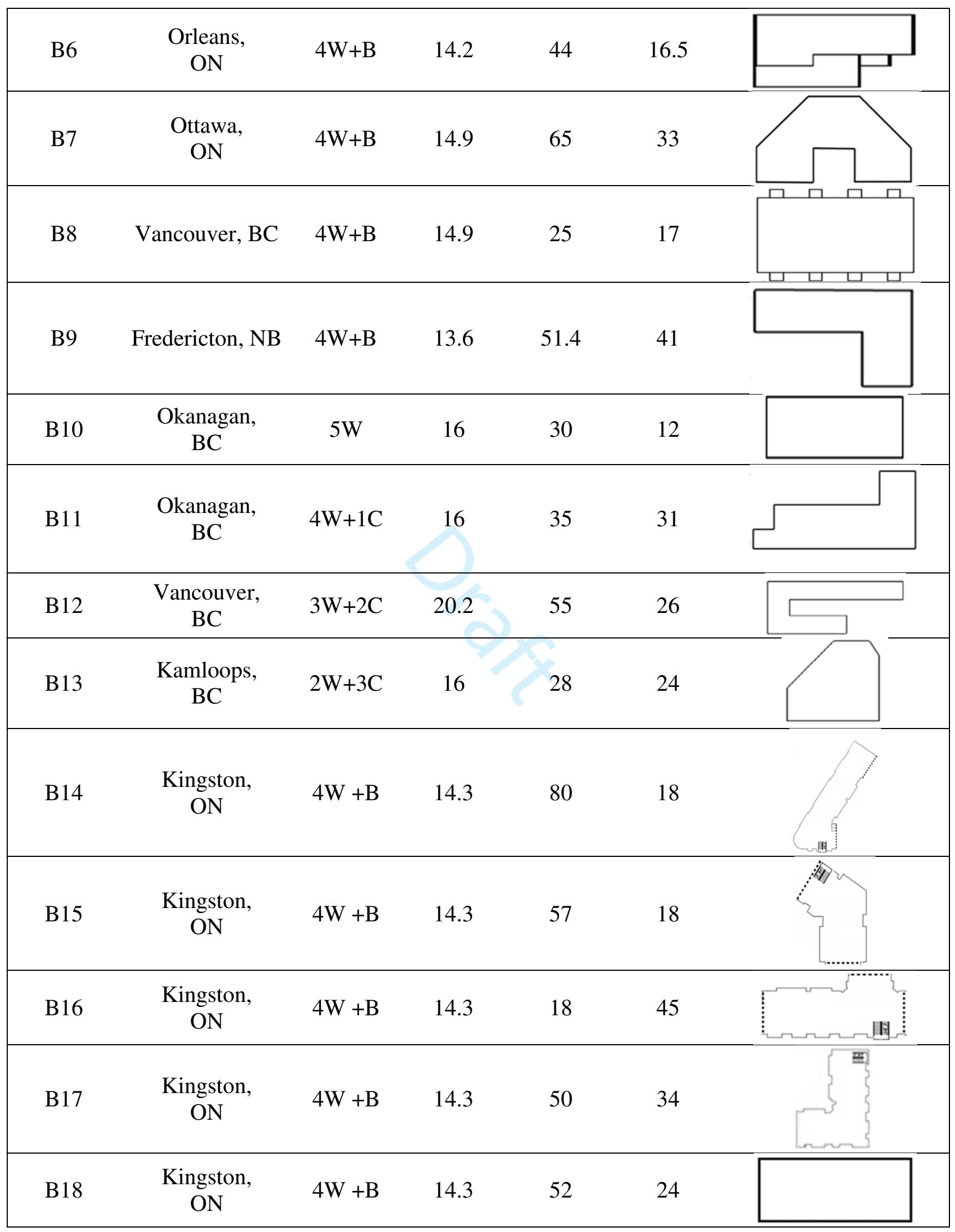




\begin{tabular}{|c|c|c|c|c|c|c|}
\hline B19 & $\begin{array}{c}\text { Kingston, } \\
\text { ON }\end{array}$ & $4 \mathrm{~W}+\mathrm{B}$ & 16.79 & 52 & 32 & \\
\hline B20 & $\begin{array}{l}\text { Kingston, } \\
\text { ON }\end{array}$ & $3 \mathrm{~W}+\mathrm{B}$ & 15.8 & 51 & 30 & \\
\hline B21 & $\begin{array}{c}\text { Kingston, } \\
\text { ON }\end{array}$ & $3 \mathrm{~W}+\mathrm{B}$ & 15.8 & 26 & 15 & \\
\hline B22 & $\begin{array}{l}\text { Ottawa, } \\
\text { ON }\end{array}$ & $3 \mathrm{~W}+\mathrm{B}$ & 12 & 20 & 9 & \\
\hline B23 & $\begin{array}{l}\text { Ottawa, } \\
\text { ON }\end{array}$ & $3 \mathrm{~W}+\mathrm{B}$ & 11.83 & 18.7 & 9.4 & 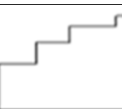 \\
\hline B24 & $\begin{array}{l}\text { Ottawa, } \\
\text { ON }\end{array}$ & $3 \mathrm{~W}+\mathrm{B}$ & 11.83 & 18.7 & 9.4 & \\
\hline B25 & $\begin{array}{l}\text { Ottawa, } \\
\text { ON }\end{array}$ & $3 \mathrm{~W}+\mathrm{B}$ & 10.11 & 15 & 12 & \\
\hline B26 & $\begin{array}{c}\text { Orleans, } \\
\text { ON }\end{array}$ & $3 \mathrm{~W}+\mathrm{B}$ & 12.3 & 36 & 18 & \\
\hline B27 & $\begin{array}{c}\text { Orleans, } \\
\text { ON }\end{array}$ & $3 \mathrm{~W}+\mathrm{B}$ & 12.3 & 18 & 15 & \\
\hline B28 & $\begin{array}{l}\text { Ottawa, } \\
\text { ON }\end{array}$ & $3 \mathrm{~W}+\mathrm{B}$ & 12.3 & 18 & 15 & \\
\hline B29 & $\begin{array}{l}\text { Ottawa, } \\
\text { ON }\end{array}$ & $3 \mathrm{~W}+\mathrm{B}$ & 12.3 & 18 & 15 & \\
\hline B30 & $\begin{array}{l}\text { Ottawa, } \\
\text { ON }\end{array}$ & $2 \mathrm{~W}+\mathrm{B}$ & 6.4 & 20 & 7.6 & \\
\hline B31 & $\begin{array}{l}\text { Orleans, } \\
\text { ON }\end{array}$ & $4 \mathrm{~W}$ & 14.28 & 50 & 24 & \\
\hline B32 & $\begin{array}{l}\text { Orleans, } \\
\text { ON }\end{array}$ & $4 \mathrm{~W}$ & 14.28 & 41 & 24 & \\
\hline B33 & $\begin{array}{l}\text { Orleans, } \\
\text { ON }\end{array}$ & $3 \mathrm{~W}+\mathrm{B}$ & 13.1 & 18 & 15 & \\
\hline B34 & $\begin{array}{c}\text { Orleans, } \\
\text { ON }\end{array}$ & $3 \mathrm{~W}+\mathrm{B}$ & 13.1 & 18 & 15 & \\
\hline
\end{tabular}




\begin{tabular}{|c|c|c|c|c|c|}
\hline B35 & $\begin{array}{c}\text { Boucherville, } \\
\text { QC }\end{array}$ & $2 W$ & 6 & 9.7 & 9.4 \\
\hline B36 & $\begin{array}{l}\text { Longueuil, } \\
\text { QC }\end{array}$ & $2 \mathrm{~W}$ & 6 & 9.1 & 6.7 \\
\hline B37 & $\begin{array}{c}\text { Brossard, } \\
\text { QC }\end{array}$ & $2 \mathrm{~W}$ & 6 & 8.5 & 7.3 \\
\hline B38 & $\begin{array}{l}\text { Brossard, } \\
\text { QC }\end{array}$ & $2 \mathrm{~W}$ & 6 & 9.7 & 9.4 \\
\hline B39 & $\begin{array}{l}\text { Brossard, } \\
\text { QC }\end{array}$ & $2 \mathrm{~W}$ & 6 & 9.1 & 7.3 \\
\hline B40 & $\begin{array}{l}\text { Brossard, } \\
\text { QC }\end{array}$ & $1 \mathrm{~W}$ & 3 & 10.3 & 8.5 \\
\hline B41 & $\begin{array}{l}\text { Kamloops, } \\
\text { BC }\end{array}$ & $4 \mathrm{~W}$ & 3 & 70 & 50 \\
\hline B42 & Okanagan, BC & $5 \mathrm{~W}$ & 16 & 61 & 35 \\
\hline B43 & Kingston, ON & $4 \mathrm{~W}+\mathrm{B}$ & 16.79 & 80 & 56 \\
\hline B44 & Kingston, ON & $3 \mathrm{~W}+\mathrm{B}$ & 15.8 & 56 & 51 \\
\hline B45 & Orleans, ON & $3 \mathrm{~W}+\mathrm{B}$ & 12.3 & 54 & 15 \\
\hline B46 & Orleans, ON & $4 \mathrm{~W}$ & 14.28 & 91 & 24 \\
\hline B47 & Kingston, ON & $4 \mathrm{~W}+\mathrm{B}$ & 14.3 & 96 & 80 \\
\hline
\end{tabular}

* W, C and B represent wood, reinforced concrete and basement, respectively.

\section{AVT INSTRUMENTATION AND DATA COLLECTION}

160 Six Tromino sensors were used to measure the ambient motion (acceleration and velocity) of the

161 building floors in three orthogonal directions (see example in Figure 1). Each sensor is equipped

162 with three high gain orthogonal electrodynamic velocimeters, three low gain orthogonal

163 electrodynamic velocimeters, and three orthogonal digital accelerometers. 


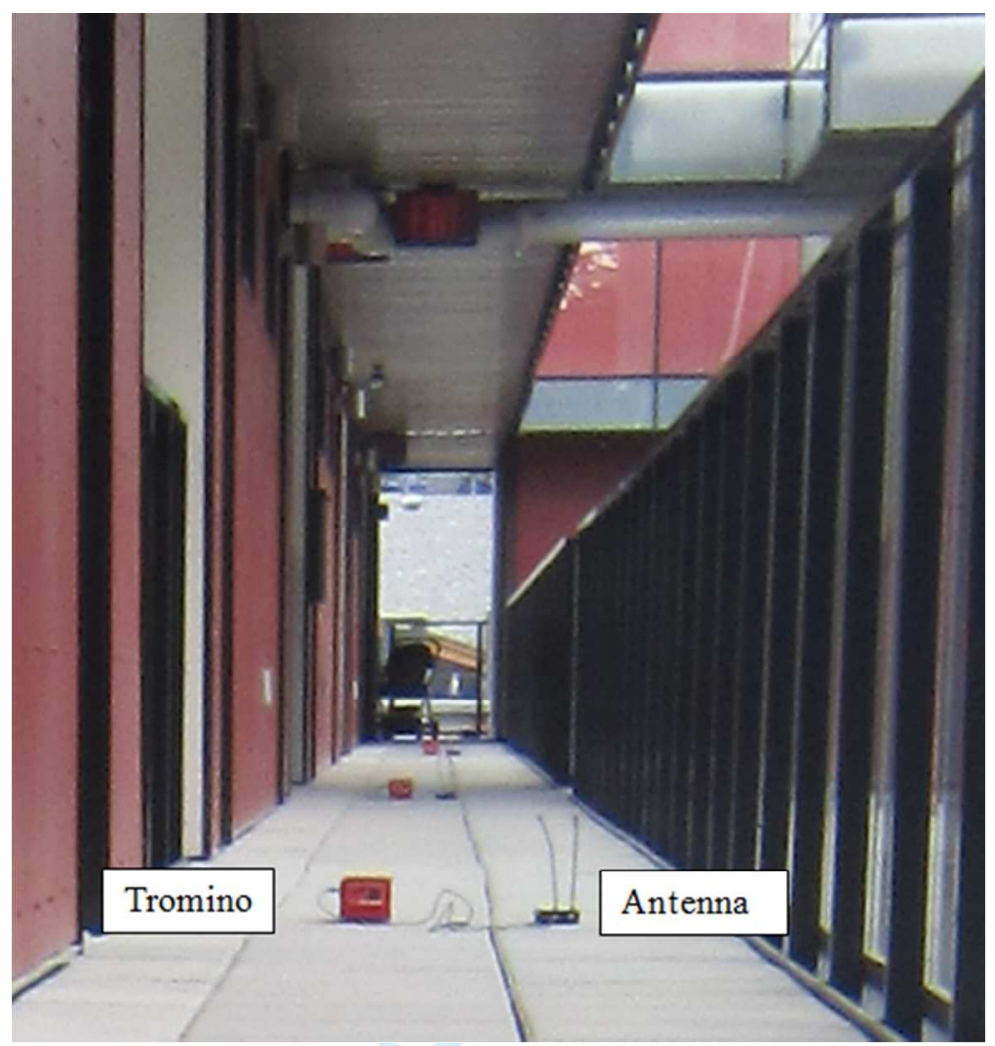

Figure 1 Tromino® (sensor) with radio antenna during data collection of building B18

As shown in Figure 1, the sensors have compact portable size and weight, and are kept in

167 position without any anchorage to the floor. Their acquisition frequency range is $0.1-256 \mathrm{~Hz}$ and

168 the signal is transmitted using radio waves. Multiple sensors were used for each test set-up, and

169 several set-ups were used for each building. A master (reference) sensor was placed at a fixed

170 location with good signal (that is with relatively large motion, typically on top floor or roof if

171 accessible) and multiple roving sensors were moved to the pre-identified locations determined by

172 studying building plans and access considerations. To obtain an accurate modal response,

173 synchronization of the recorded signals is essential; the sensors form a wireless chain and their

174 synchronization is achieved using radio antennas. Figure 2 shows a schematic radio network

175 among the master sensor (S1) and the roving sensors (S2, S3, S4, S5 and S6) used on a typical

176 floor of building B9. The building response was recorded for eight consecutive minutes for each 
177 measurement setup at the sampling frequency of $128 \mathrm{~Hz}$. The basic principle of AVT is that 178 excitation forces are undefined and the recorded response is assumed to be a broadband, 179 stationary Gaussian white noise, with approximately equal energy content throughout the 180 frequency range of interest (Bendat and Piersol 2000).

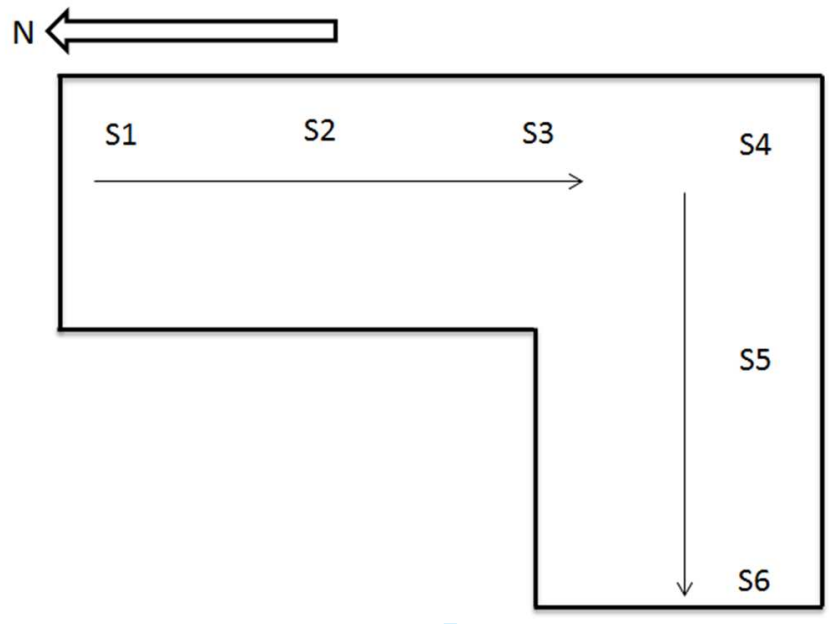

182 The recorded signals of each sensor are the floor velocity and acceleration components measured 183 in two orthogonal horizontal (in the case of building B9, North-South and East-West) and Up184 Down directions. Vertical acceleration and velocity records were removed from the raw 185 measurements as the modal extraction makes use of only horizontal velocities in this project. 186 Figure 3 shows an example of a recorded horizontal velocity component in Building B9. 


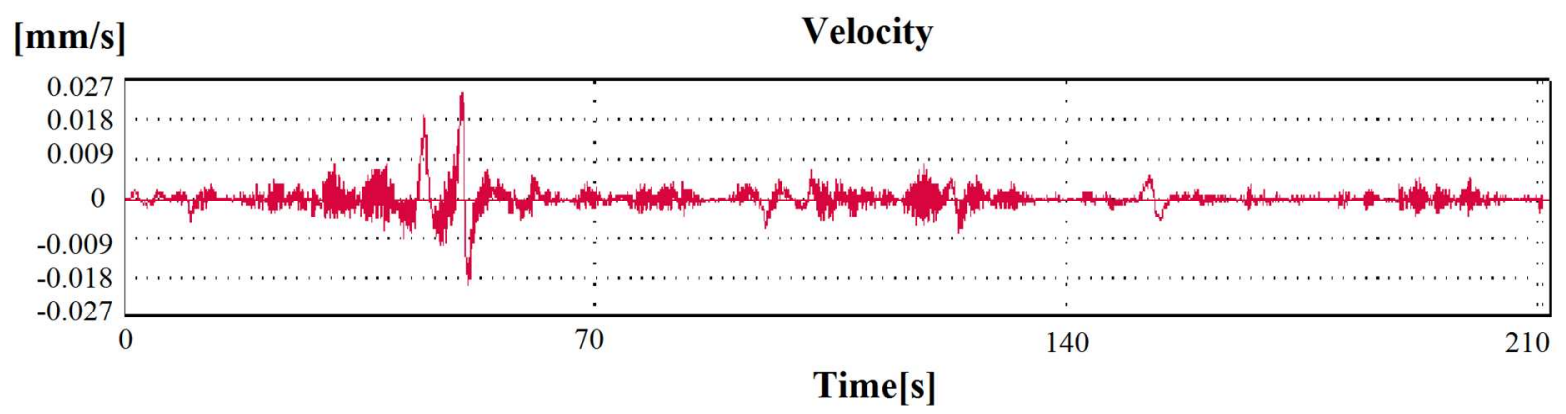

Figure 3 Example of velocity record for building B9

\section{EFDD ANALYSIS OF RECORDED MEASUREMENTS}

191 ARTeMIS Extractor (Structural Vibration Solutions A/S, 2010) software was used in this

192 research to process synchronized records and allow extraction of modal building parameters such

193 as natural frequencies, mode shapes and approximate equivalent internal damping ratios using a

194 technique called enhanced frequency domain decomposition (EFDD). This method proceeds

195 with the estimation of the spectral density function (SDF) of each time record, which describes

196 the energy distribution of the motion with respect to frequency. Singular value (eigenvalue)

197 decomposition (SVD) of each PSD matrix is performed giving $n$ sets of singular vectors

198 (eigenvectors) corresponding to $n$ measured configurations, which represent an approximation of

199 the building natural frequencies and mode shapes. The singular values obtained from each of the

$200 n$ measured configurations are averaged by normalizing the area under the preceding singular

201 value curve. These averaged singular values are plotted against frequency to offer potential peaks

202 for identification of the building's natural frequencies excited by ambient sources. A single-

203 degree-of-freedom (SDOF) bell-shaped function is produced for each measured configuration,

204 by considering all frequencies in the vicinity of the resonant frequency (potential peak) and the

205 modal parameters are identified in the neighborhood of the peak point of this SDOF spectral

206 bell-shaped function, as illustrated in Figure 4. Typically, peaks defined by the bell curve are in 
207 fact narrow frequency bands that may contain more than a single natural mode, as illustrated 208 below for Building B9.

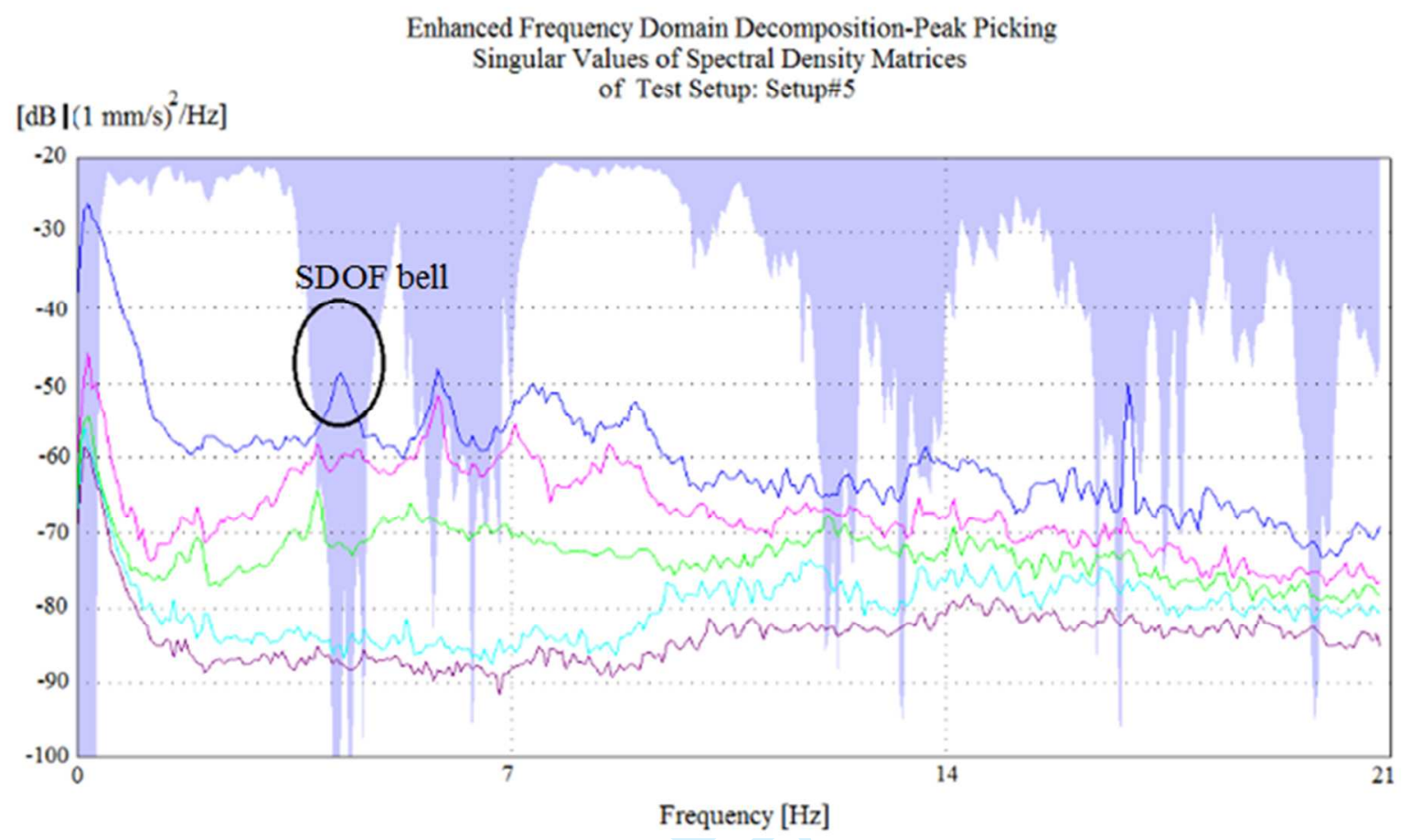

Figure 4 Singular value plot showing SDOF bell-shaped function, building B9

210 An estimate of the damping ratio for each identified natural sway frequency mode is obtained by

211 converting the SDOF bell-shaped function to time domain using Inverse Fast Fourier Transform

212 (IFFT) and calculating its logarithmic decrement. It is noteworthy to mention that the equivalent

213 damping ratio is only a rough approximation, considering the many signal manipulations leading

214 to its determination and the fact that structural damping is not typically viscous in nature

215 (logarithmic decrement). An example of the two fundamental mode shapes for Building B9

216 extracted from the recorded measurements can be seen in Figure 5, as displayed by the

217 ARTeMIS software. The AVT-extracted properties of the buildings are listed in Table 2. It

218 should be noted that the dash in Table 2 indicates that no value could be extracted from the

219 records due to high noise. 
220 Table 2 Measured natural periods and estimated modal damping ratios of wood-frame

221 buildings

\begin{tabular}{|c|c|c|c|c|}
\hline \multirow{2}{*}{ Building ID } & \multicolumn{2}{|c|}{ Natural Period (s) } & \multicolumn{2}{|c|}{ Estimated Modal Damping Ratio (\%) } \\
\hline & Transverse & Longitudinal & Transverse & Longitudinal \\
\hline B1 & 0.20 & 0.29 & - & 6.0 \\
\hline B2 & 0.29 & 0.31 & 2.3 & 2.9 \\
\hline B3 & 0.46 & 0.35 & 3.8 & 2.7 \\
\hline B4 & 0.37 & 0.29 & 2.5 & 1.8 \\
\hline B5 & 0.28 & 0.35 & 4.5 & 5.5 \\
\hline B6 & 0.20 & 0.19 & 4.3 & 2.4 \\
\hline B7 & 0.25 & 0.23 & 4.6 & 3.1 \\
\hline B8 & 0.40 & 0.25 & 2.3 & 2.2 \\
\hline B9 & 0.20 & 0.19 & 3.7 & - \\
\hline B10 & 0.26 & 0.23 & - & 1.5 \\
\hline B11 & 0.22 & 0.27 & 2.4 & 2.2 \\
\hline B12 & 0.29 & 0.32 & 2.1 & 2.3 \\
\hline B13 & 0.32 & 0.19 & 4.7 & 4.1 \\
\hline B14 & 0.33 & 0.23 & 1.4 & 3.2 \\
\hline B15 & 0.31 & 0.29 & 2.2 & 4.6 \\
\hline B16 & 0.29 & 0.27 & 2.3 & 3.3 \\
\hline B17 & 0.27 & 0.22 & 2.1 & 4.0 \\
\hline B18 & 0.24 & 0.19 & 3.4 & - \\
\hline B19 & 0.23 & 0.18 & 1.2 & 1.4 \\
\hline B20 & 0.23 & 0.26 & 1.0 & - \\
\hline B21 & 0.27 & - & 1.4 & - \\
\hline B22 & 0.18 & 0.14 & 3.1 & 4.6 \\
\hline B23 & 0.21 & 0.23 & 1.1 & 3.7 \\
\hline B24 & 0.35 & 0.29 & 1.9 & 1.1 \\
\hline B25 & 0.20 & 0.17 & 1.8 & 1.5 \\
\hline B26 & - & 0.24 & - & 2.6 \\
\hline B27 & 0.29 & 0.23 & 1.4 & 3.2 \\
\hline B28 & 0.26 & 0.29 & - & 1.1 \\
\hline B29 & 0.26 & 0.32 & 3.3 & 2.2 \\
\hline B30 & 0.20 & 0.12 & 1.9 & 1.3 \\
\hline B31 & 0.20 & 0.16 & 2.2 & 1 \\
\hline B32 & 0.21 & 0.16 & 1.7 & 3.8 \\
\hline
\end{tabular}




\begin{tabular}{|ccccc|}
\hline B33 & 0.22 & 0.28 & 5.7 & - \\
\hline B34 & 0.24 & 0.28 & 3.6 & - \\
\hline B35 & 0.13 & - & - & - \\
\hline B36 & 0.15 & - & 7.3 & - \\
\hline B37 & 0.14 & - & - & - \\
\hline B38 & 0.12 & - & 4 & - \\
\hline B39 & 0.17 & - & 3.4 & - \\
\hline B40 & 0.11 & - & - & 2.3 \\
\hline B41 & - & 0.26 & - & 1.2 \\
\hline B42 & 0.26 & 0.21 & 1.4 & 2.8 \\
\hline B43 & 0.21 & 0.19 & 1.1 & 1.3 \\
\hline B44 & 0.26 & 0.24 & 1.9 & 0.23 \\
\hline B45 & 0.23 & 0.28 & 1.4 & - \\
\hline B46 & 0.19 & 0.16 & 3.3 & \\
\hline B47 & 0.21 & 0.23 & & - \\
\hline
\end{tabular}

$\begin{array}{ll}\text { a) Longitudinal mode shape, } \mathrm{T}=0.19 \mathrm{~s} & \text { b) Transversal mode shape, } \mathrm{T}=0.20 \mathrm{~s}\end{array}$

\section{Figure 5 Test results of Building B9}

227 Several numerical modeling techniques have been used by various researchers to simulate the

228 behaviour of light-frame wood structures with shear walls (e.g. Folz and Filiatrault 2004; Collins

229 et al. 2005a; 2005b; Doudak et al. 2005; and Casagrande et al. 2015). In the present study, 
230 selected buildings from the database were modeled using the commercial software SAP2000®

231 (Computers and Structures 2016). The selection of the buildings was based on the availability of

232 detailed building information obtained from the structural drawings including the building area,

233 shearwall location and length, as well as details about the shearwall construction details such as

234 nail size and spacing, sheathing thickness and hold-down type. The goal of this part of the study

235 is to develop a simplified analytical model that would mimic the dynamic behavior of light-

236 frame buildings at a level of loading consistent with that experienced by the structure when AVT

237 is conducted.

238 Simplified 3D linear elastic models of the building structures were created in order to determine

239 their fundamental sway period in each principal direction. The structural model was assumed to

240 be pinned at its base and the floor diaphragms are assumed to be perfectly rigid. The building

241 masses were lumped at the centroid of each floor and the rotational moment of inertia of the

242 floor diaphragm was accounted for in the model. The in-plane lateral stiffness of the wood shear

243 walls was estimated using the deflection equation provided in the Canadian timber design

244 standard, CSA O86 Engineering Design in Wood (CSA 2014). The developed building models

245 were validated using ambient vibration tests results of natural frequencies and mode shapes. For

246 this purpose, the initial stiffness of shear walls, denoted as $\mathrm{K}_{(0-10) \%}$, was determined and assumed

247 to represent the level of loading at ambient conditions. A simplified 3D linear elastic model of 248 Building B9 is shown in Figure 6. 


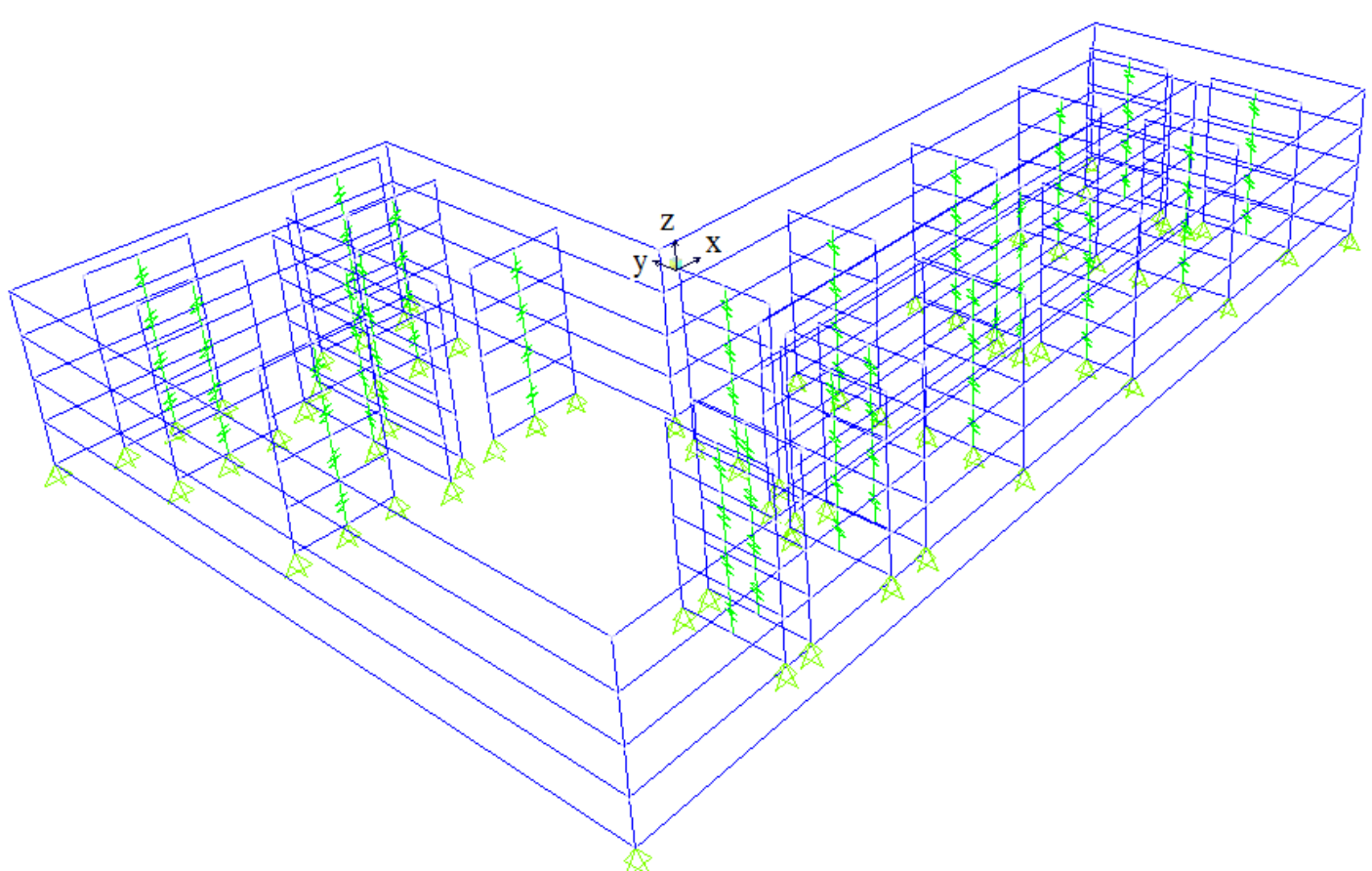

250 Once the FE model results were validated with field results at stiffness $\mathrm{K}_{(0-10) \%}$, the models were

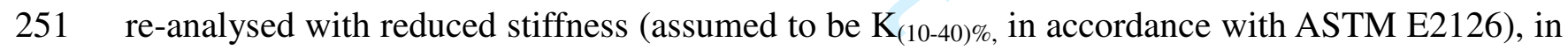

252 order to predict the fundamental period of wood buildings exposed to seismic action. The FE

253 models were also modified to capture the vertical effects of hold-down wall anchors whose

254 motion is activated during an earthquake, by introducing a vertical spring representative of the

255 hold-downs vertical stiffness.

\section{RESULTS AND DISCUSSION}

\section{Comparison between Computed and Measured Building Periods}

259 Table 3 compares the computed and measured periods at ambient level obtained for the buildings 260 selected for analysis. Significant differences are observed in a few particular cases, such as the 
261 longitudinal period of buildings B9, B43 and B45. These differences are mainly attributed to

262 construction configuration or irregular plan shape. On average, the FE models overestimate the

263 periods in the transverse and logitudinal directions by $13 \%$ and $23 \%$, respectively. It is expected

264 that the model would yield higher periods compared to the field measurements as the model is

265 based on linear assumptions while the initial stiffness in real wood buildings is nonlinear and

266 affected by connection behavior. Also, the model does not account for any contribution of

267 windows, doors and other architectural finishes and components which may contribute to the

268 lateral stiffness of the building, while their mass is taken into consideration.

269 Table 3 Natural periods of tested buildings vs. FE model results

\begin{tabular}{|ccccccc|}
\hline Buildings & \multicolumn{2}{c}{ T (s) } & \multicolumn{2}{c|}{ Comparison } \\
\hline & \multicolumn{2}{c}{ Field Results } & \multicolumn{2}{c|}{ Model Results } & Model/test & Model/test \\
\hline & Trans & Long & Trans & Long & Trans & Long \\
\hline B5 & 0.28 & 0.35 & 0.30 & 0.40 & 1.07 & 1.14 \\
\hline B6 & 0.20 & 0.19 & 0.22 & 0.23 & 1.10 & 1.21 \\
\hline B9 & 0.20 & 0.19 & 0.22 & 0.28 & 1.10 & 1.47 \\
\hline B22 & 0.18 & 0.14 & 0.19 & 0.17 & 1.06 & 1.21 \\
\hline B25 & 0.20 & 0.17 & 0.22 & 0.20 & 1.10 & 1.18 \\
\hline B43 & 0.21 & 0.19 & 0.25 & 0.26 & 1.19 & 1.37 \\
\hline B44 & 0.26 & 0.24 & 0.27 & 0.28 & 1.04 & 1.17 \\
\hline B45 & 0.23 & 0.28 & 0.27 & 0.38 & 1.17 & 1.36 \\
\hline B46 & 0.19 & 0.16 & 0.21 & 0.19 & 1.11 & 1.19 \\
\hline
\end{tabular}

271 Comparison with NBCC and literature

272 The fundamental period results from the current study were compared with the expressions

273 developed based on data points obtained during low level earthquake shaking and forced

274 vibration tests conducted by Camelo (2003) and the expression in the NBCC (2015) edition. In

275 order to compare the AVT results with earthquake-level shaking data, a best fit line (with

276 coefficient of correlation $\mathrm{R}^{2}=0.58$ ) was drawn through the AVT data from the current study (see

277 Figure 7 and Figure 8). The same best fit line is modified using Kharrazi's (2006) models to 
278 predict periods at low and high level ground shaking (Equations (2) and (3)) are included in

279 Figure 8.

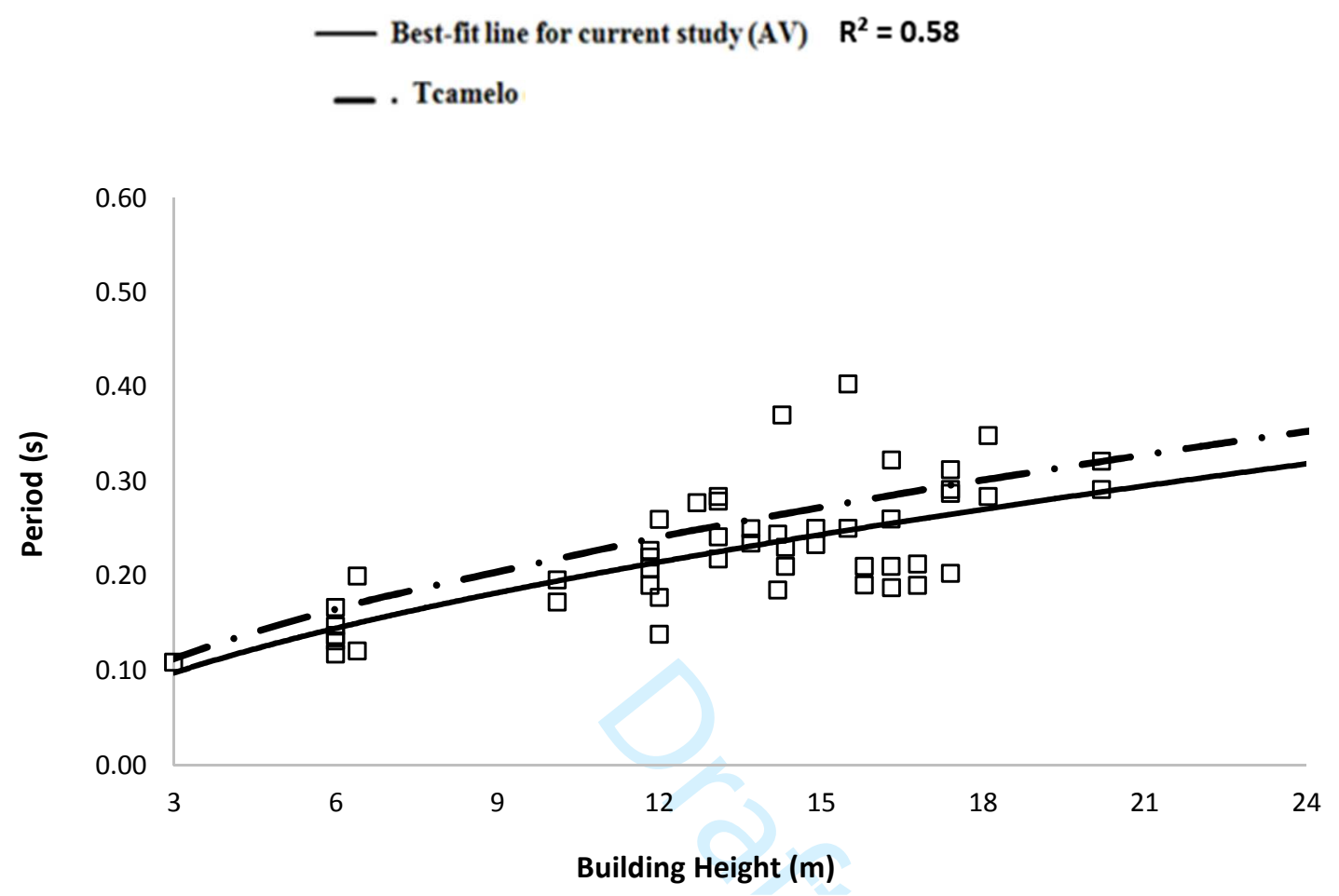

280 Figure 7 Comparison of fundamental periods obtained from Current study (AVM test 


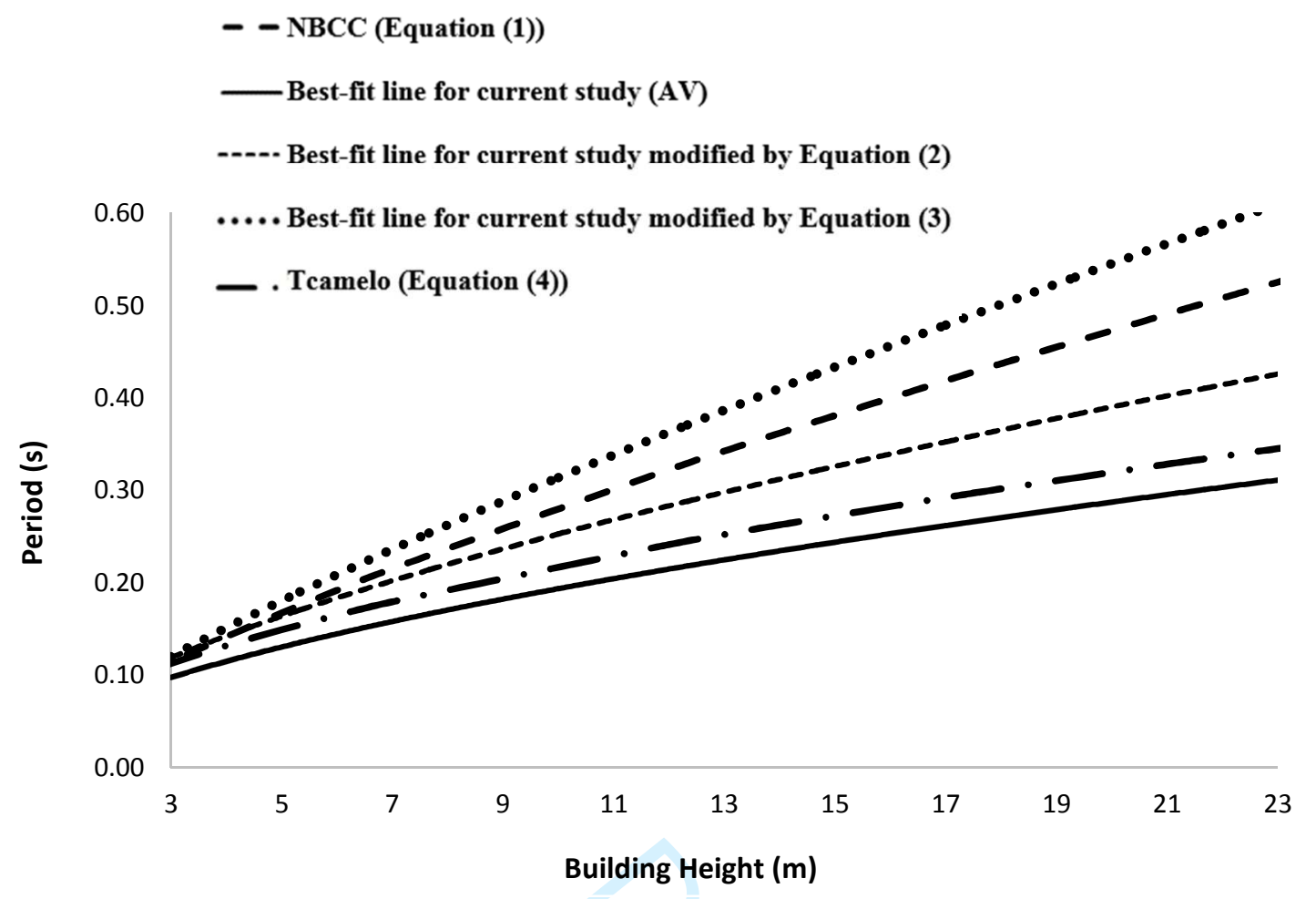

Figure 8 Comparison of fundamental periods obtained from NBCC equation, Equation (2),

285 Figure 7 shows that Equation (4) (Camelo, 2003) provides slightly higher period values than 286 those extracted from the AVM tests. However, in Figure 8 (omitting the data points of Figure 7) 287 Camelo's expression provides smaller periods than those obtained with Equations (2) and (3). As 288 expected, the periods calculated using the NBCC formula for seismic analysis are larger than 289 those extracted from AVM tests and calculated using Equation (4) and Equation (2) (for low 290 ground shaking). It is also seen that the NBCC curve lies between the best fit lines of the two 291 Kharrazi's models for predicting seismic periods representing low and strong ground shaking 292 (Equation (2) and Equation (3)). This observation is consistent with the assumption that the 293 NBCC formula is developed based on moderate-level ground shaking, but the main issue 294 remains its large uncertainty since the only variable considered is the building height. The main 
295 difficulty in comparing any level of vibration testing results with the NBCC expression stems

296 from the fact that the NBCC equation is not defined for a specific level of seismic loading or

297 vibration amplitude. From the comparison presented in Figure 8, Equation (2) appears reasonable

298 and conservative for modifying the building period measured at ambient conditions.

\section{Comparison with period equation for wind response}

300 Whereas a modification of the measured periods at AVT level is needed for seismic design, AVT 301 periods can be directly compared with the code expression for the wind response period. In 302 Figure 9, the natural frequencies of several tested structures (from the current study and from 303 literature (Feldmann 2015; Camelo 2003; Ellis and Bougard 2001; and Kharrazi 2001)) are 304 compared with the curve in Eurocode EC 1 Part 1-4 (2010) (Equation (5) where $h$ is in m).

$$
n_{1}=\frac{46}{h}
$$

305 The plot in Figure 9 shows that Equation (5) provides a reasonable estimate of the fundamental 306 frequencies when compared with the tested structures.

307 A least-square curve fit with coefficient of correlation $\mathrm{R}^{2}=0.74$ was used to approximate the 308 measured points from the current study, resulting in Equation (6), which provides estimates only 309 slightly lower than the Eurocode formula.

$$
n_{1}=44 / h
$$

310 Given the variability in field measurements and the uncertainty associated with such crude

311 estimates of the fundamental building period, it can be concluded that the experimental results

312 obtained in the current study provide further validation of the Eurocode equation for the purpose 
313 of wind design.

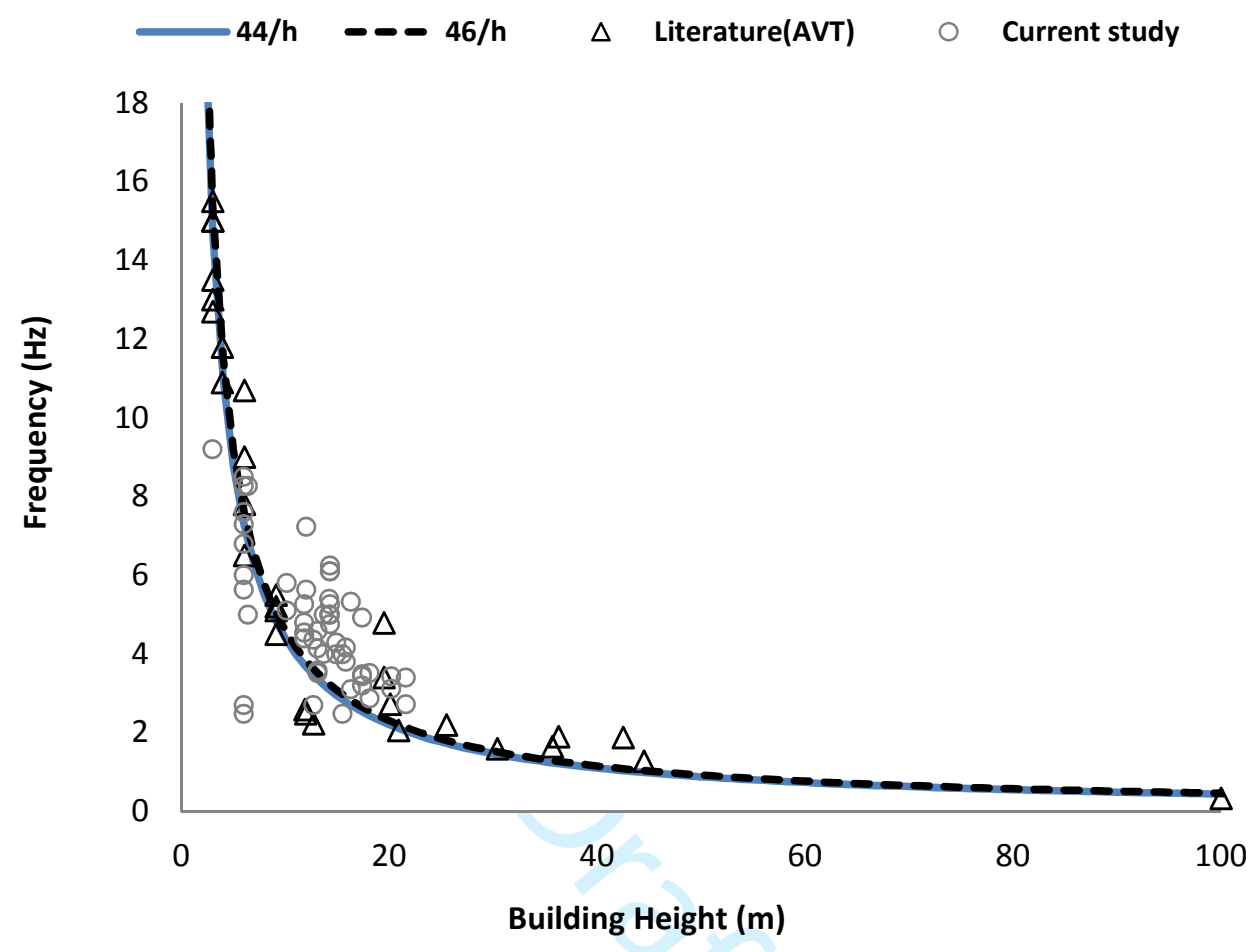

317 The current study shows that Equation (1) provides higher period estimates than the measured

318 (AV) for wood shear wall buildings, and that considering the building height as the only variable

319 in the period equation is not sufficient to describe the dynamic characteristics of light-frame

320 wood structures. NBCC (2015) allows the use of so-called rational analysis methods other than

321 the empirical equation (Equation (1)) with the limit that the calculated period shall not exceed

322 twice the value obtained from Equation (1). In this part of the study, a simplified period

323 estimation method is suggested for light-frame wood buildings, based on the Rayleigh

324 approximation expressed in Equation (7). 
$T=2 \pi \sqrt{\frac{\sum_{x=1}^{n}\left(W_{x} \delta_{x}^{2}\right)}{g \sum_{x=1}^{n}\left(F_{x} \delta_{x}\right)}}$

325 Where $W_{x}, F_{x}$ are the seismic weight, and the force at level x, respectively, and $\delta_{x}$ is the elastic

326 lateral displacement due to force $F_{x}, n$ is total number of floors, and $\mathrm{g}$ is acceleration due to

327 gravity. $\delta_{x}$ is taken as $1 / k$, where $k$ is the lateral stiffness provided by shear walls at level $\mathrm{x}$.

328 Nine buildings with known geometric and structural information, were studied to assess whether

329 the stiffness of shear walls can be expressed as a function of their length (see Figure 10). The 330 selection was made based on the availability of construction details and structural drawings,

331 including the dimensions of the building, the location and length of the shearwalls.

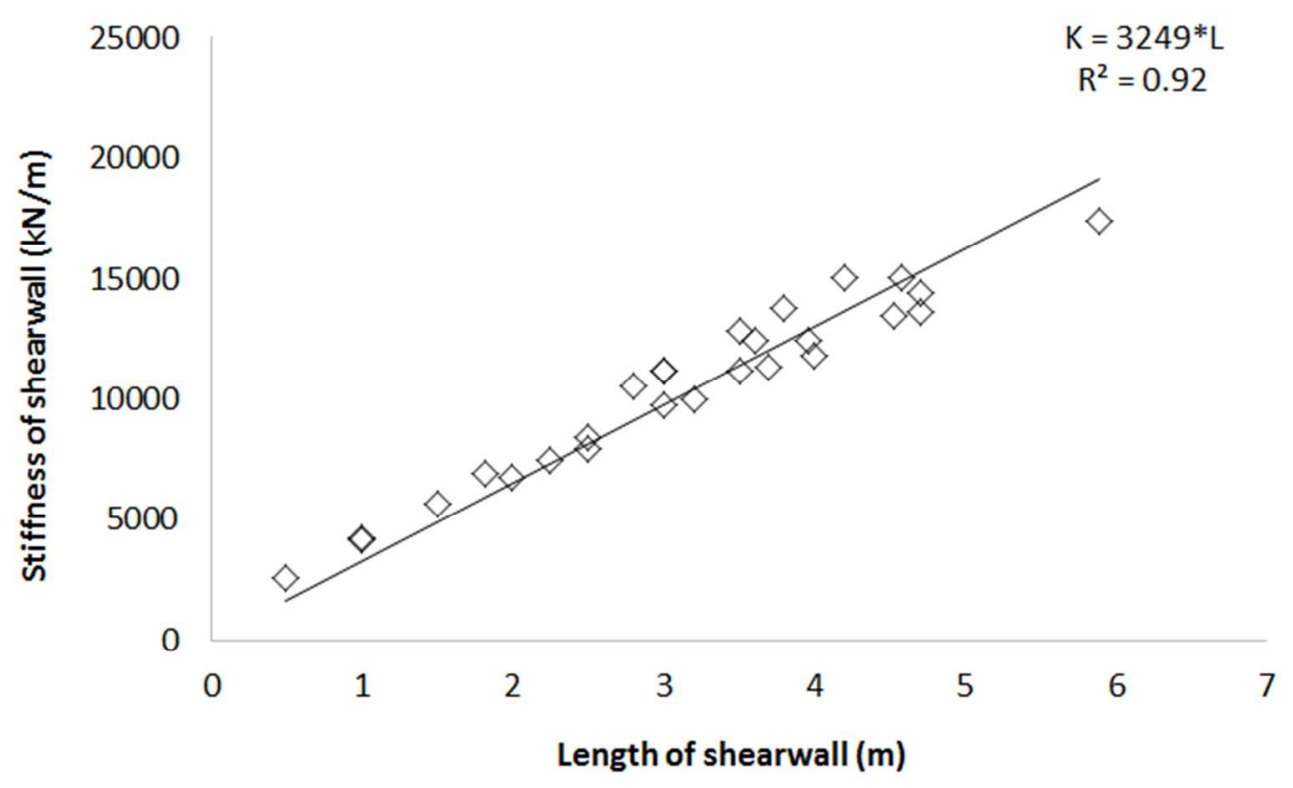


334 This simple method of estimating the period for wood shear wall buildings was validated by 335 comparing the periods calculated by Rayleigh approximation $\left(\mathrm{T}_{\text {Rayleigh }}\right)$ with those obtained using 336 the AVT measurements ( $\left.\mathrm{T}_{\text {measured }}\right)$. The correlation between $\mathrm{T}_{\text {Rayleigh }}$ and $\mathrm{T}_{\text {measured }}$ is displayed in 337 Figure 11, where the dashed reference line represents the ideal fit.

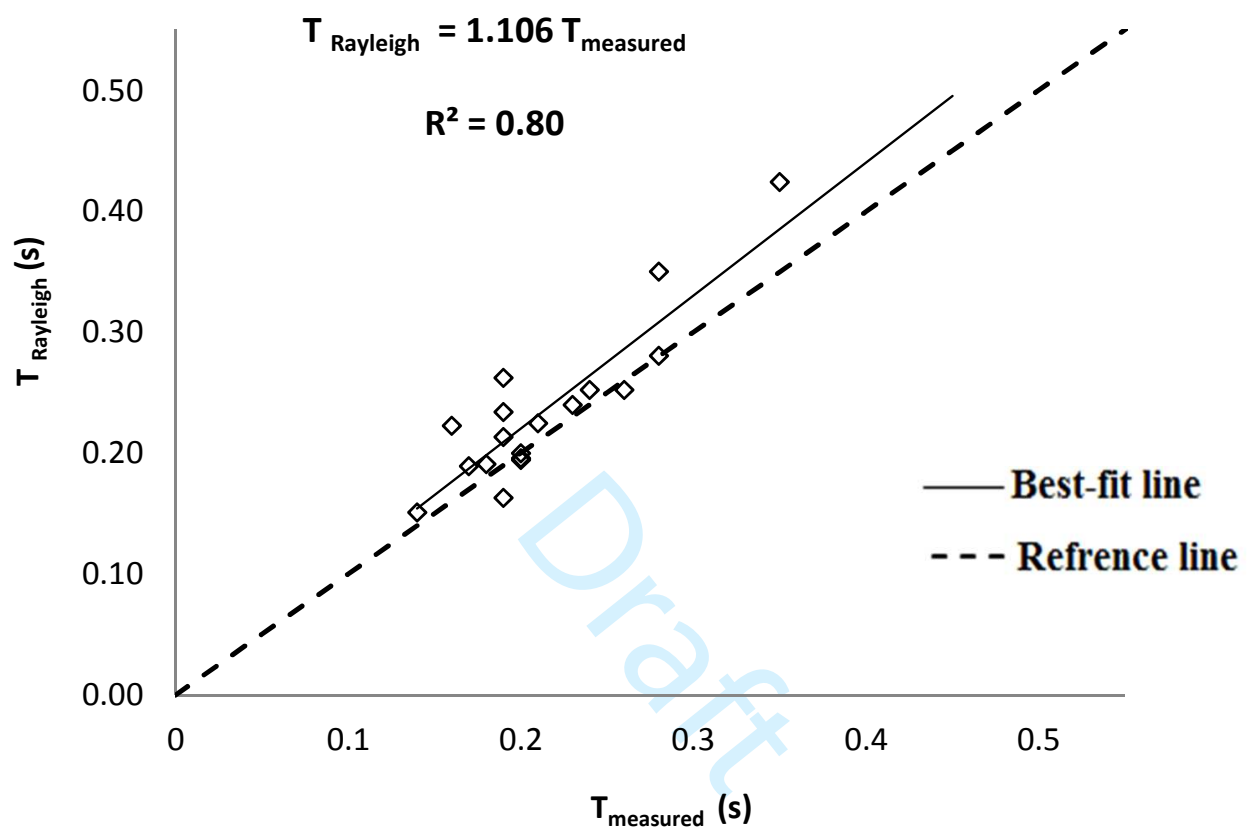

Figure 11 Correlation between AVT measured and Rayleigh periods

$339 \mathrm{~T}_{\text {Rayleigh }}$ is also compared with the fundamental periods obtained by finite element modeling $340 \quad\left(\mathrm{~T}_{\text {model }}\right)$ in Table 4. 
344 Table 4 Periods from AVT measurements, finite element modeling and Rayleigh

345 approximation

\begin{tabular}{|ccccccc|}
\hline \multirow{2}{*}{$\begin{array}{c}\text { Buildings } \\
\text { ID }\end{array}$} & \multicolumn{9}{c}{ Measured } & \multicolumn{2}{c|}{ Rayleigh } & \multicolumn{2}{c|}{ Model } \\
\cline { 2 - 7 } & Trans & Long & Trans & Long & Trans & Long \\
\hline B5 & 0.28 & 0.35 & 0.28 & 0.42 & 0.30 & 0.40 \\
\hline B6 & 0.20 & 0.19 & 0.19 & 0.21 & 0.22 & 0.23 \\
\hline B9 & 0.20 & 0.19 & 0.20 & 0.26 & 0.22 & 0.28 \\
\hline B22 & 0.18 & 0.14 & 0.19 & 0.15 & 0.19 & 0.17 \\
\hline B25 & 0.20 & 0.17 & 0.20 & 0.19 & 0.22 & 0.2 \\
\hline B43 & 0.21 & 0.19 & 0.22 & 0.23 & 0.25 & 0.26 \\
\hline B44 & 0.26 & 0.24 & 0.25 & 0.25 & 0.27 & 0.28 \\
\hline B45 & 0.23 & 0.28 & 0.24 & 0.35 & 0.27 & 0.38 \\
\hline B46 & 0.19 & 0.16 & 0.16 & 0.22 & 0.21 & 0.19 \\
\hline
\end{tabular}

346 Figure 12 shows a good correlation $\left(R^{2}=0.91\right)$ between the periods obtained by FE modeling 347 and by Rayleigh approximation using shear wall length to represent lateral stiffness.

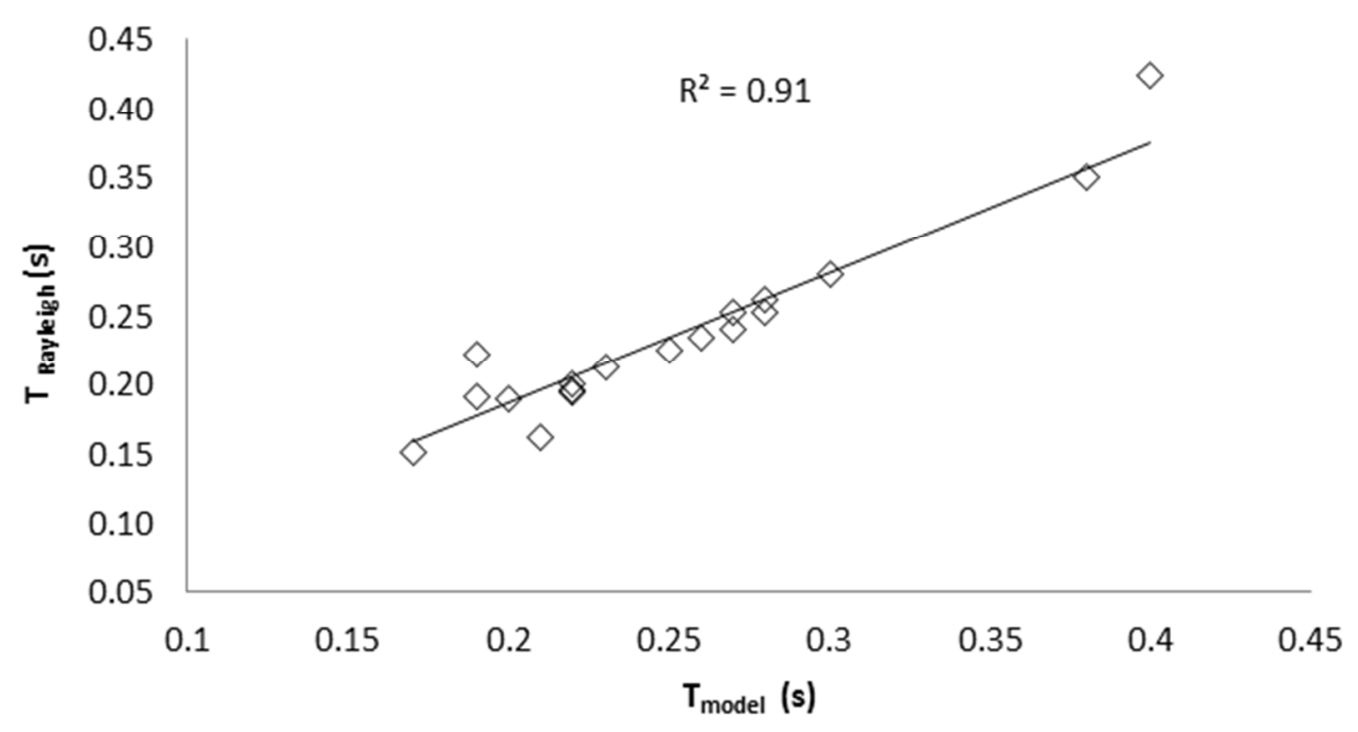

349 Considering the above comparisons and the inherent variability of measurements and modeling 
350 approximations, it can be concluded that the simple method of Rayleigh approximation 351 considering lateral stiffness as a function of the length of wood shear walls, provides a 352 reasonable fundamental period estimate for light-frame wood buildings. It does overestimate the 353 measured results, but is nonetheless a good estimation when measurements are not available.

354 Proposed Period Formula for Light-Frame Wood Buildings

355 As discussed previously, a large spread was observed in the measured data when plotted against 356 the building code period formula, which is solely a function of the building height. Figure 13 357 reiterates this observation, showing a poor coefficient of correlation of $\mathrm{R}^{2}=0.27$. This has 358 motivated the derivation of a better expression of the fundamental period for wood-frame 359 buildings, as discussed next.

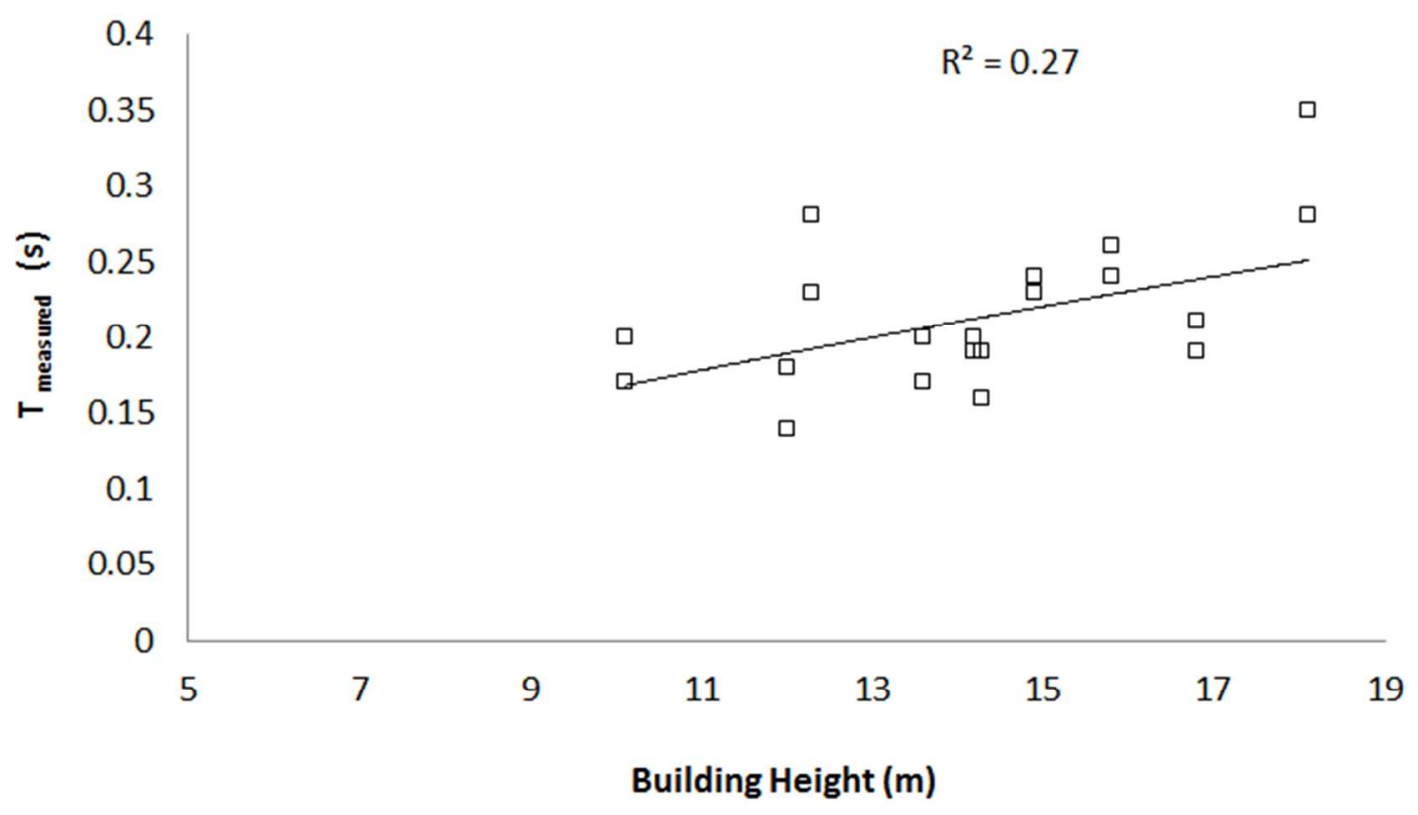


361 Basic structural dynamics principles indicate that a building fundamental period is a function of 362 the building mass and lateral stiffness. The building mass can be estimated with reasonable 363 accuracy but since the majority of the mass is concentrated in the floors the floor area can be 364 used to estimate the mass. Similarly, the shear wall stiffness can be approximated by the wall 365 length aligned in the direction of interest. These practical simplifications allow the designer to 366 evaluate a preliminary seismic design of a building before specific details are decided. To 367 evaluate the fundamental building period dependency on these variables (height, stiffness and 368 mass), the measured periods are plotted against $\left(\frac{h}{l} * A\right)$ for the two orthogonal directions in 369 Figure 14, where $h$ is the building height, $l$ is the total shear wall length in a given main 370 orientation, and $\mathrm{A}$ is the total floor area.

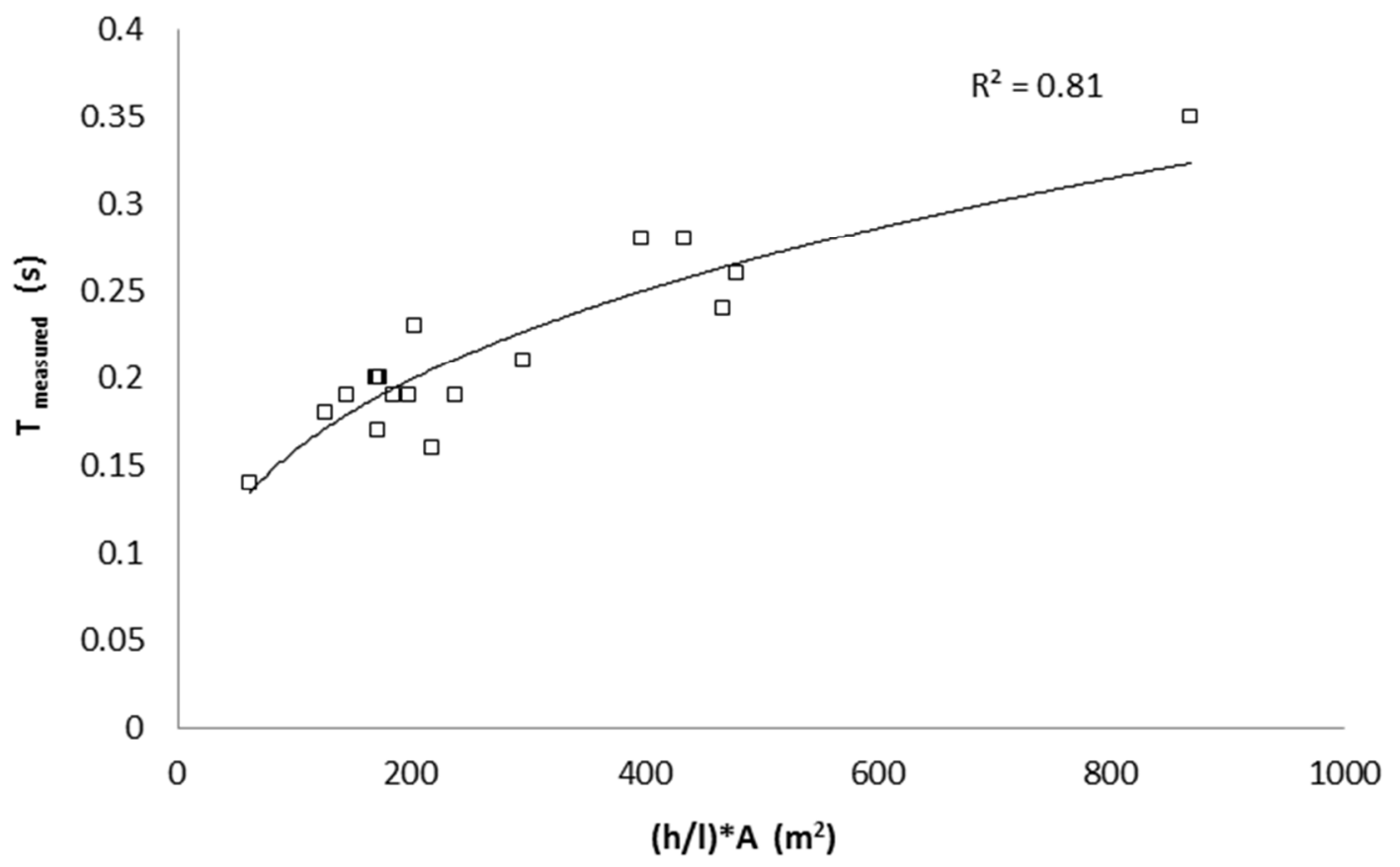


372 It can clearly be seen from Figure 14 that the scatter in the measured data is less $\left(\mathrm{R}^{2}\right.$ value of

373 0.81) than that presented in Figure 13 where only the building height was considered $\left(\mathrm{R}^{2}\right.$ value

374 of 0.27$)$. For completeness, Table 5 gives the values of $\left(\frac{h}{l} * A\right)$ for each considered building.

375 Table 5 Natural periods of tested buildings vs. $\left(\frac{h}{l} * A\right)$ parameter

\begin{tabular}{|ccccc|}
\hline \multirow{2}{*}{ Building ID } & \multicolumn{2}{c}{$\frac{\boldsymbol{h}}{\boldsymbol{l}} * \boldsymbol{A}\left(\mathbf{m}^{\mathbf{2}}\right)$} & \multicolumn{2}{c|}{ Measured Periods (s) } \\
\cline { 2 - 5 } & Trans & Long & Trans & Long \\
\hline B5 & 434 & 814 & 0.28 & 0.35 \\
\hline B6 & 173 & 197 & 0.20 & 0.19 \\
\hline B9 & 170 & 184 & 0.20 & 0.19 \\
\hline B22 & 127 & 61 & 0.18 & 0.14 \\
\hline B25 & 172 & 172 & 0.20 & 0.17 \\
\hline B43 & 296 & 237 & 0.21 & 0.19 \\
\hline B44 & 479 & 468 & 0.26 & 0.24 \\
\hline B45 & 203 & 398 & 0.23 & 0.28 \\
\hline B46 & 145 & 206 & 0.19 & 0.16 \\
\hline
\end{tabular}

376 The regression in Figure 14 presents a significant improvement over that found in the building

377 code for wood shear walls; however, since the best fit equation is based on measurements at

378 ambient vibration level, it cannot be used directly for estimating building period for the purpose

379 of calculating seismic base shear. In order to shift the proposed period expression to a level

380 appropriate for seismic design, the expression developed by Kharrazi (Equation (2)) was used.

381 The final form of the proposed period formula is presented in Equation (8), where values for

$382 \alpha=0.045$ and $\beta=0.36$ are obtained by regression analysis that minimizes the error between the

383 data points and the fit expression.

$T=0.045\left(\frac{h}{l} * A\right)^{0.36}$

384 A comparison of the building periods obtained by ambient vibration measurements, NBCC 
385 formula (Equation (1)), Camelo's period formula (Equation (4)) and that estimated using 386 Equation (8) is presented in Figure 15 and Figure 16 for the transverse and longitudinal building 387 directions, respectively.

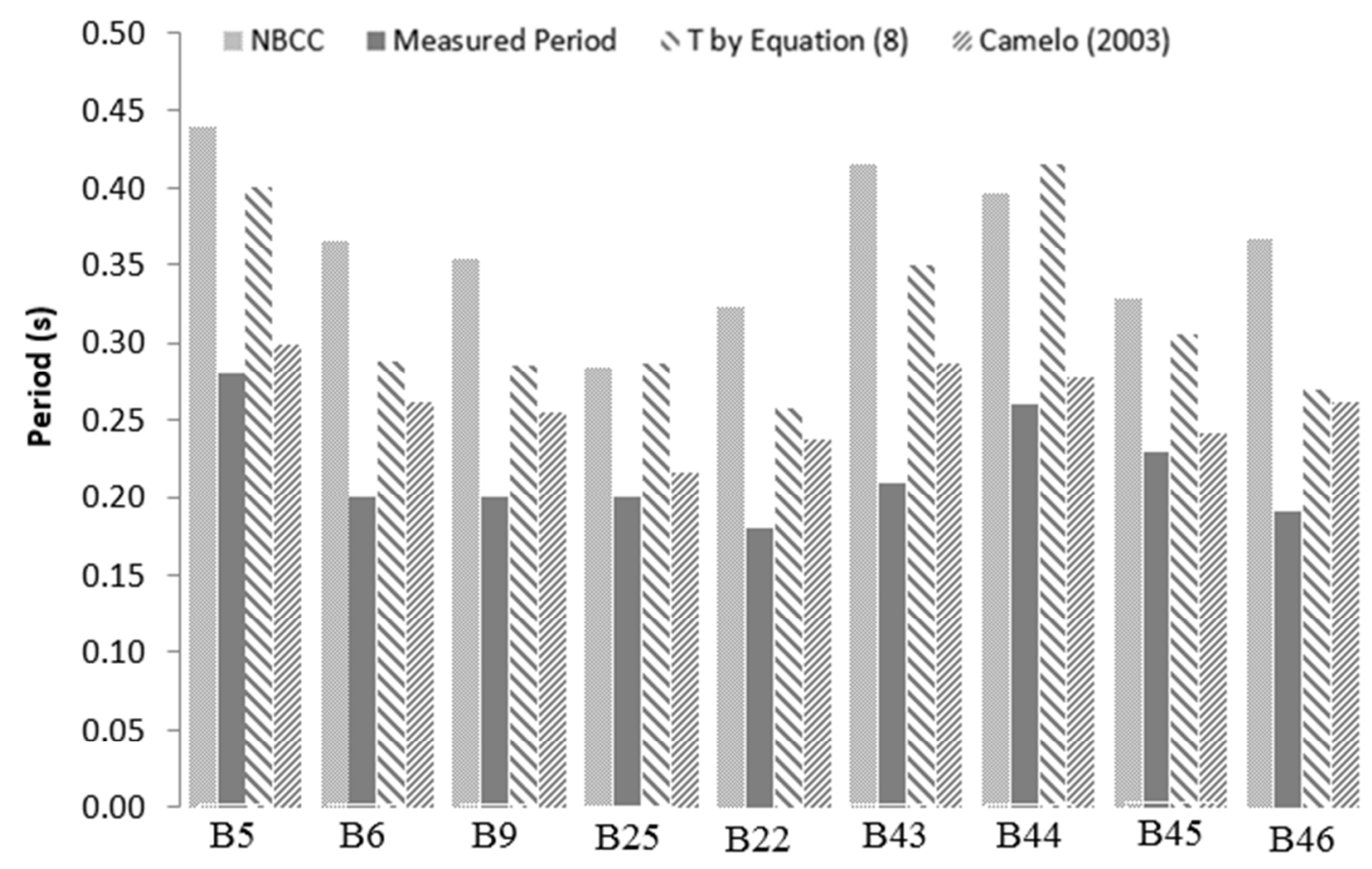

388 Figure 15 Comparison of measured periods, code periods and periods by Equation (7) 389 (Transverse direction) 


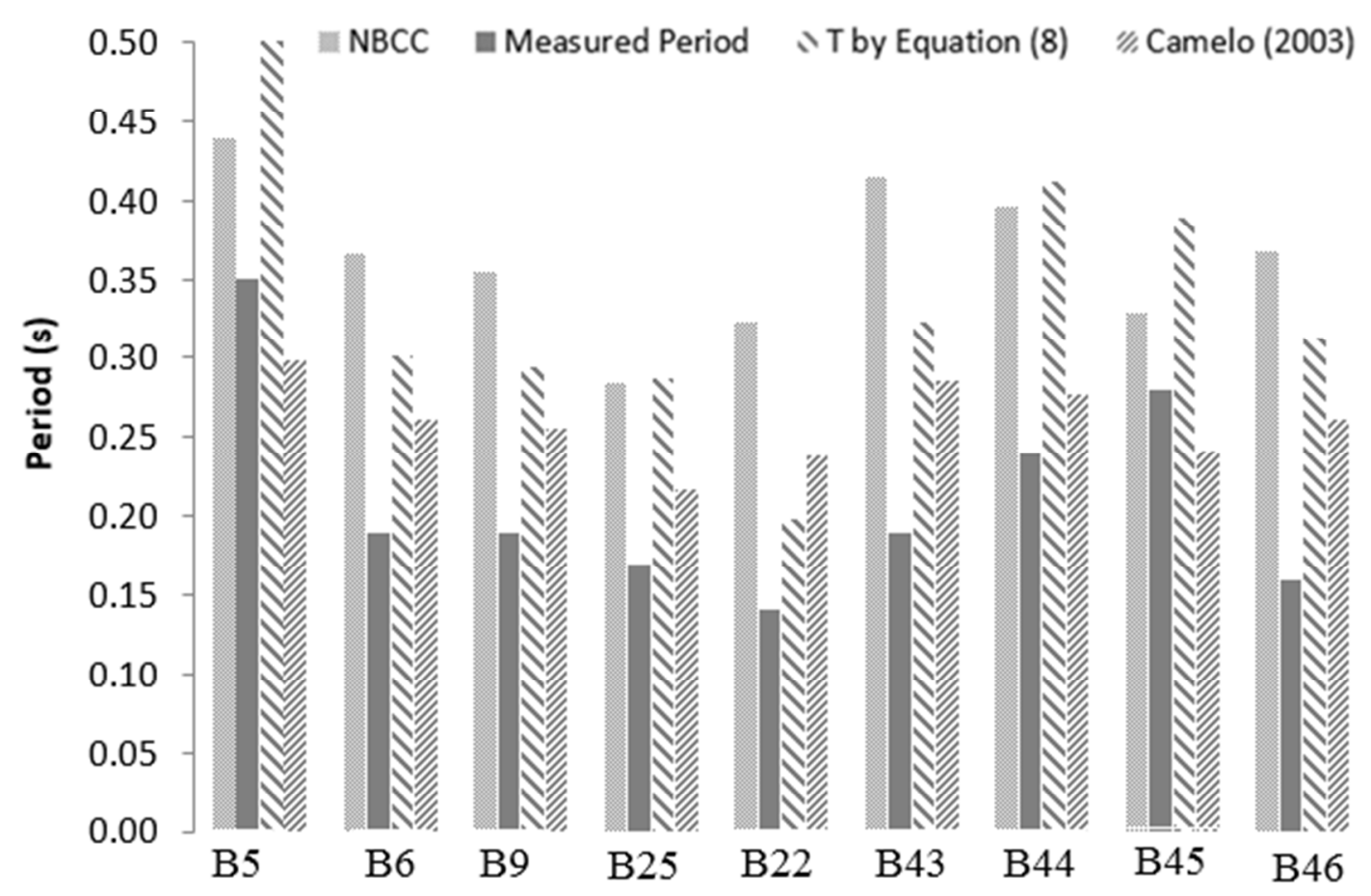

Figure 16 Comparison of measured periods, code periods and periods by Equation (7)

392 With a few exceptions, it can be observed from these figures that the proposed expression

393 (Equation (8)) yields period values that are lower than those obtained using the NBCC formula

394 (Equation (1)) and higher than those using Camelo's period formula (Equation (4)). It should be 395 noted that Camelo's formula depends only on building height and therefore is not capable of 396 predicting different results in different principal directions. It should be emphasized that the 397 above analysis and proposed new period formula are predicated on the fact that Kharrazi's 398 equation (Equation (2)) is appropriate to modify AVT periods to earthquake level values. 399 Furthermore, the methodology used here extrapolates Kharrazi's equation and assumes it is valid 400 for taller wood buildings (up to six storey) than those used in its development (1-3 storeys). 
401 The proposed expression is based on results from nine buildings only and it therefore should be

402 considered as a rough, conservative estimate. When more buildings with known construction 403 details are added to the database, the trends can be affirmed with less uncertainty and a more 404 reliable expression can be developed.

\section{CONCLUSION}

406 The main objective of this study was to evaluate the adequacy of the NBCC formula for 407 estimating the fundamental period of wood buildings, and develop a more reliable method of 408 predicting the fundamental period of light-frame wood buildings. A comprehensive data base of 409 measured dynamic properties of light-frame wood building has been compiled based on ambient 410 vibration tests. Using a simplified method of period estimation based on the Rayleigh 411 approximation while using the building mass and replacing the stiffness of shear walls by their 412 length showed reasonable fit when compared with the FE model results and AVT measured 413 periods.

414 Regression analysis on the measured data showed that a conservative better estimate of the 415 building period (compared to the NBCC formula) can be obtained when the building height, 416 floor area and shear wall length are included in the analysis. A formula was developed based on 417 these geometric parameters and it was shown to provide a reasonably good fit with the measured 418 results with a coefficient of correlation of $\mathrm{R}^{2}$ in the order of 0.80 . In general, the proposed 419 formula yields period values that are lower than those obtained using the NBCC formula. AVT 420 on more buildings with known construction details are needed to further refine the proposed 421 expression. 


\section{References}

424 ASTM. 2011. Standard test methods for cyclic (reversed) load test for shear resistance of vertical

425 elements of the lateral force resisting systems for buildings. ASTM E2126-11, American Society

426 for Testing and Materials. West Conshohocken, PA, U.S.A.

427 Applied Technology Council (ATC) 1978. Tentative provisions for the development of seismic

428 regulations for buildings. Report No. ATC 3-06, Applied Technology Council, Palo Alto, 429 California, U.S.A.

430 Bendat, J., S., and Piersol, A., G. 2000. Random data: Analysis and measurement procedures, 3rd 431 ed., John Wiley \& Sons, Inc., New York.

432 Computers and Structures, I.C., SAP 2000-advanced, 2016.

433 Casagrande, D., Rossi, S., Sartori, T., \& Tomasi, R. 2015. Proposal of an analytical procedure 434 and a simplified numerical model for elastic response of single-storey timber shear-walls. 435 Construction and Building Materials, 102: 1102-1112.

436 Canadian Standards Association (CSA), 2014. CAN/CSA O86-14 Engineering design in wood, 437 Ontario, Canada.

438 Collins, M., Kasal, B., Paevere, P., and Foliente, G., C. 2005a. Three-dimensional model of light 439 frame wood buildings. I: Model description. Journal of Structural Engineering, 131(4): 676-683.

440 Collins, M., Kasal, B., Paevere, P., and Foliente, G., C. 2005b. Three-dimensional model of light 441 frame wood buildings. II: Experimental investigation and validation of analytical model. Journal 442 of Structural Engineering, 131(4): 684-692. 
443 Camelo, V., S. 2003. Dynamic characteristics of wood frame buildings. Doctoral dissertation, 444 California Institute of Technology, Pasadena, California, U.S.A.

445 Costa Rican Seismic Code 1986. Seismic Code of Costa Rica. Federal College of Engineers and 446 Architects of Costa Rica, San Jose, Costa Rica.

447 Doudak, G., McClure, G., Smith, I., Hu, L., and Stathopoulos, T. 2005. Monitoring structural 448 response of a wooden light-frame industrial shed building to environmental loads. Journal of 449 Structural Engineering, 131(5): 794-805.

450 Eurocode 1 2010. Actions on Structures - Part 1-4: General Actions - Wind Actions. BS EN 451 1991-1-4:2005+A1:2010. BSI, April 2010.

452 Ellis, B., R., and Bougard, A., J. 2001. Dynamic testing and stiffness evaluation of a six-storey 453 timber framed building during construction. Engineering Structures, 23(10): 1232-1242.

454 Feldmann, A, S. 2015. Dynamic properties of tall timber structures under wind induced 455 vibration. Master thesis, Technische Universität München, Germany.

456 Farsi, M. N., and Bard, P. Y. 2004. Estimation des périodes propres de bâtiments et vulnérabilité 457 du bâti existant dans l'agglomération de Grenoble. Revue Française de Génie Civil, 8(2-3) : 149458179.

459 Folz, B., and Filiatrault, A. 2004. Simplified seismic analysis of woodframe structures. 13th 460 World Conference on Earthquake Engineering, Vancouver, Canada.

461 Federal Emergency Management Agency (FEMA-450) 2003. NEHRP, recommended provisions 462 for seismic regulations for new buildings and other structures, Part 1: Provisions, Washington 

(DC).

464 Gilles, D., and McClure, G. 2012. Measured natural periods of concrete shear walls buildings: 465 Insights for the design of Canadian buildings. Canadian Journal. of Civil Engineering, 39(8): $466 \quad 867-877$.

467 Goel, R., K., and Chopra, A., K. 1998. Period formulas for concrete shear wall buildings. Journal 468 of Structural Engineering, 124(4): 426-433.

469 Hafeez, G., Mustafa, A., Doudak, G., McClure, G. 2014. Predicting the fundamental period of 470 light-frame wood buildings, Journal of Performance of Constructed Facilities, ASCE 28: $471 \quad$ A4014004.

472 Kharrazi, M. H., and Ventura, C. E. 2006. Vibration frequencies of woodframe residential 473 construction. Earthquake spectra, 22(4): 1015-1034.

474 Kharrazi, M., H., K. 2001. Vibration characteristics of single-family woodframe building. Master 475 Thesis, University of British Columbia, Vancouver, Canada.

476 Lee, L. H., Chang, K. K., and Chun, Y. S. 2000. Experimental formula for the fundamental 477 period of RC buildings with shear-wall dominant systems. The Structural Design of Tall 478 Buildings, 9(4): 295-307.

479 Lagomarsino, S. 1993. Forecast models for damping and vibration periods of buildings. Journal 480 of Wind Engineering and Industrial Aerodynamics, 48(2): 221-239.

481 Nikoo, M., Hadzima-Nyarko, N., Khademi, M., Mohasseb, F. 2017. Estimation of fundamental 482 period of reinforcedconcrete shear wall buildings using self-organization feature map. Structural 
483 Engineering \& Mechanics 63(2):237-249.

484 NRC/IRC. 2015. National Building Code of Canada 2015. National Research Council of Canada, 485 Institute for Research in Construction, Ottawa, Ontario.

486 National Earthquake Hazards Reduction Program (NEHRP). 1994. Recommended provisions for 487 the development of seismic regulations for new buildings. Building Seismic Safety Council, 488 Washington, D.C.

489 Structural Vibration Solutions A/S. 2011. ARTeMIS Extractor Handy (Version 5.3) [Software], 490 http://www.svibs.com

491 Saatcioglu, M., and Morales, M. 2011. Computation of fundamental period for seismic design of 492 reinforced concrete buildings. CSCE Annual General Meeting \& Conference, Ottawa, Canada.

493 S.P.A., M. 2008. Manuale tromino ENG TR-ENGY PLUS October 2008, http://www.tromino.eu

494 Saatcioglu, M., and Humar, J. 2003. Dynamic analysis of buildings for earthquake-resistant 495 design. Canadian Journal of Civil Engineering, 30(2): 338-359.

496 SEAOC. 1999. Recommended lateral force requirements and commentary (SEAOC Blue Book).

497 Seismology Committee, Structural Engineers Association of California, Sacramento, CA.

498 Uniform Building Code 1997. Structural engineering design provisions. International conference 499 of building officials, Vol. 2. 